\title{
HPLC-Profiles of Tocopherols, Sugars, and Organic Acids in Three Medicinal Plants Consumed as Infusions
}

\author{
Custódio Lobo Roriz, Lillian Barros, Ana Maria Carvalho, and Isabel C. F. R. Ferreira \\ Mountain Research Centre (CIMO), ESA, Polytechnic Institute of Bragança, Campus de Santa Apolónia, Apartado 1172, \\ 5301-855 Bragança, Portugal \\ Correspondence should be addressed to Lillian Barros; lillian@ipb.pt and Isabel C. F. R. Ferreira; iferreira@ipb.pt
}

Received 11 August 2014; Revised 24 September 2014; Accepted 24 September 2014; Published 7 October 2014

Academic Editor: Jaime Yanez

Copyright (C) 2014 Custódio Lobo Roriz et al. This is an open access article distributed under the Creative Commons Attribution License, which permits unrestricted use, distribution, and reproduction in any medium, provided the original work is properly cited.

\begin{abstract}
Pterospartum tridentatum (L.) Willk, Gomphrena globosa L., and Cymbopogon citratus (DC.) Stapf are medicinal plants that require a more detailed chemical characterization, given the importance of their consumption as infusions. Therefore, the individual profiles in tocopherols, free sugars, and organic acids were obtained by high performance liquid chromatography (HPLC) coupled to different detectors (fluorescence, refraction index, and photodiode array, resp.). C. citratus revealed the highest content of $\alpha$-, and total tocopherols, glucose, sucrose, succinic, and ascorbic acids. P. tridentatum presented the highest fructose and total sugars content. Otherwise, G. globosa showed the highest organic acids concentration. As far as we know, this is the first study reporting the mentioned chemical compounds in G. globosa and C. citratus.
\end{abstract}

\section{Introduction}

For a long time, plants represented one of the most important therapies for different diseases. Nowadays, the popular use of plants as a way of treatment is still very important for human beings [1]. Pterospartum tridentatum (L.) Willk, Gomphrena globosa L., and Cymbopogon citratus (DC.) Stapf are examples of those plants that are widely used in folk medicine, mostly as infusions.

P. tridentatum (family: Fabaceae) is a European endemic species and its flowers infusion is used against liver, bladder, kidney, and rheumatism problems; it is also used for high blood pressure, cough, kidney stones, diabetes, and bronchitis $[1,2]$.

G. globosa (family: Amaranthaceae) is native from Panama and Guatemala and its aqueous extract of its purple inflorescences is good to treat bronchial asthma, acute and chronic bronchitis, and whooping cough; the infusion of the flowers is used to treat oliguria and indigestion, also as expectorant and pertussis $[3,4]$.

C. citratus (family: Poaceae) is native from the Southwest Asia and its aqueous extract (i.e., in the form of infusion) is used for the treatment of several inflammationbased pathologies, in digestive disorders, diabetes, nervous disorders, and fever [5-7]. According to Novais et al. [1], the infusion is used as gastric analgesic, intestinal antiinflammatory, and renal antispasmodic and for gall-bladder ailments, sea-sickness, and bladder ailments.

There are several reports about the biological activity of the mentioned plants, especially concerning antioxidant activity $[5,8]$, that have been related to their phenolic composition [3,9], but studies regarding the composition on primary metabolites and nutrients are scarce. Moreover, many of the commercially available samples are wild and require chemical characterization. Besides secondary metabolites/nonnutrients such as phenolic compounds, medicinal plants contain primary metabolites and nutrients (e.g., as sugars, organic acids, and tocopherols) that need to be profiled and quantified.

Mono- and oligosaccharides, with low molecular weight, and their derivatives such as sugar alcohols display a major role in the structure and function of all living cells [10]. Organic acids are involved in several biochemical pathways, including energy production and formation of precursors for amino-acid biosynthesis [11]. Vitamin E (including tocopherols) is known to be an essential micronutrient for maintaining the health and wellbeing of humans and other 
animals. Several studies suggest that the use of vitamin E may contribute to help lowering the risks of specific chronic and degenerative diseases such as Alzheimer's disease, some types of cancer, cataracts, and ischemic heart disease [12]. All these molecules can be determined by high performance liquid chromatography (HPLC) coupled to different detectors according to their chemical properties, namely, fluorescence for tocopherols, refraction for sugars, and UV absorption for organic acids.

Therefore, the objective of the present paper was to characterize tocopherols, sugars, and organic acids in three medicinal plants (P. tridentatum, G. globosa, and C. citratus), widely consumed as infusions.

\section{Material and Methods}

2.1. Samples. Plant material of Pterospartum tridentatum (L.) Willk, Gomphrena globosa L., and Cymbopogon citratus (DC.) Stapf was purchased from Ervital, a Portuguese company in Castro Daire (Portugal). This company, settled in a high diverse mountain region (Montemuro, the Natura 2000 site), markets several certified plant materials with different origin, such as sustainable wild harvesting of spontaneous local species and organic farming of exogenous species. Pterospartum tridentatum flowers were wildly gathered in spring 2012 (respecting plant phenology and abundance) and the other studied species were grown, also in 2012, with organic farming methods. Harvested plants were processed using instorage and low temperature drying methods (solar heated air, average daily temperature around $30-32^{\circ} \mathrm{C}$ in shade conditions, and controlled relative humidity). Samples for analysis were prepared from dried plant materials provided by the company, and botanical identification was confirmed by Ana Maria Carvalho, responsible for the medicinal plant collection of the Herbarium of the Escola Superior Agrária (BRESA), of the Polytechnic Institute of Bragança (Trás-osMontes, Portugal).

2.2. Standards and Reagents. HPLC-grade acetonitrile, ethyl acetate, and $n$-hexane were purchased from Fisher Scientific (Lisbon, Portugal). L-ascorbic acid, tocopherol, sugar, and organic acid standards were purchased from Sigma (St. Louis, MO, USA). Racemic tocol (50 mg/mL) was purchased from Matreya (Pleasant Gap, PA, USA). Water was treated in Milli-Q water purification system (TGI Pure Water Systems, Greenville, SC, USA).

2.3. Tocopherols Composition. Tocopherols were determined following a previously described procedure [13]. The equipment consisted of an integrated system with a pump (Knauer, Smartline system 1000, Berlin, Germany), degasser system (Smartline manager 5000), autosampler (Jasco AS-2057, Easton, MD, USA), and a fluorescence detector (Jasco FP2020) programmed for excitation at $290 \mathrm{~nm}$ and emission at $330 \mathrm{~nm}$. The chromatographic separation was achieved with a Polyamide II $(250 \mathrm{~mm} \times 4.6 \mathrm{~mm}$ i.d. $)$ normal-phase column from YMC Waters (Dinslaken, Germany) operating at $30^{\circ} \mathrm{C}$ (7971 $\mathrm{R}$ Grace oven). The mobile phase used was a mixture of $n$-hexane and ethyl acetate $(70: 30, \mathrm{v} / \mathrm{v})$ at a flow rate of $1 \mathrm{~mL} / \mathrm{min}$, and the injection volume was $20 \mu \mathrm{L}$. The compounds were identified by chromatographic comparisons with authentic standards. Quantification was based on calibration curves obtained from commercial standards of each compound using the internal standard (IS) methodology; racemic tocol was used as IS. The results were expressed in $\mu \mathrm{g}$ per $\mathrm{g}$ of dry weight.

2.4. Sugars Composition. Free sugars were determined by high performance liquid chromatography coupled to a refraction index detector (HPLC-RI), after an extraction procedure previously described [14]. Analysis was performed by HPLC (equipment described above) using an RI detector (Knauer Smartline 2300, Berlin, Germany). Data were analyzed using Clarity 2.4 Software (DataApex). The chromatographic separation was achieved with a Eurospher 100-5 NH2 column $(4.6 \times 250 \mathrm{~mm}, 5 \mathrm{~mm}$, Knauer, Berlin, Germany) operating at $30^{\circ} \mathrm{C}$. The mobile phase was acetonitrile/deionized water, $70: 30(\mathrm{v} / \mathrm{v})$ at a flow rate of $1 \mathrm{~mL} / \mathrm{min}$. The compounds were identified by chromatographic comparisons with authentic standards. Quantification was performed using the internal standard method; melezitose was used as IS. The results were expressed in mg per $g$ of dry weight.

2.5. Organic Acids. Organic acids were determined following a procedure previously described [15]. The analysis was performed using a Shimadzu 20A series UFLC (Shimadzu Corporation, Kyoto, Japan). Separation was achieved on a SphereClone (Phenomenex, Torrance, CA, USA) reverse phase $\mathrm{C}_{18}$ column $(5 \mu \mathrm{m}, 250 \mathrm{~mm} \times 4.6 \mathrm{~mm}$ i.d. $)$ thermostated at $35^{\circ} \mathrm{C}$. The elution was performed with sulfuric acid $(3.6 \mathrm{mM})$ using a flow rate of $0.8 \mathrm{~mL} / \mathrm{min}$. Detection was carried out in a PDA (photodiode array detector), using 215 and $245 \mathrm{~nm}$ (for ascorbic acid) as preferred wavelengths. The organic acids found were quantified by comparison of the area of their peaks recorded at $215 \mathrm{~nm}$ with calibration curves obtained from commercial standards of each compound. The results were expressed in mg per $\mathrm{g}$ of dry weight.

2.6. Statistical Analysis. All the assays were carried out in triplicate, and the results are expressed as mean values and standard deviation (SD). The results were analyzed using oneway analysis of variance (ANOVA) followed by Tukey's HSD Test with $\alpha=0.05$. This treatment was carried out using SPSS v.22.0 program.

\section{Results and Discussion}

The chemical composition of the three plant species in tocopherols, free sugars, and organic acids is presented in Table 1. C. citratus gave the highest $\alpha$ - and total tocopherols content but did not present $\delta$-tocopherol that was found in the other two species (e.g., Figure 1(a)). Tocopherols are lipidsoluble antioxidants, being $\alpha$-tocopherol the most active isoform, due to its role in lipid peroxidation inhibition [16]. These molecules are widely used as functional ingredients in food, pharmaceutical, and cosmetic preparations [17]. 
TABLE 1: Composition of P. tridentatum, G. globosa, and C. citratus in tocopherols, sugars, and organic acids (mean \pm SD).

\begin{tabular}{|c|c|c|c|}
\hline & Pterospartum tridentatum & Gomphrena globosa & Cymbopogon citratus \\
\hline$\alpha$-Tocopherol & $7.21 \pm 0.01^{b}$ & $0.38 \pm 0.04^{\mathrm{c}}$ & $56.05 \pm 2.47^{\mathrm{a}}$ \\
\hline$\gamma$-Tocopherol & $5.81 \pm 0.56^{\mathrm{a}}$ & $3.02 \pm 0.08^{\mathrm{b}}$ & $4.52 \pm 0.76^{\mathrm{a}}$ \\
\hline$\delta$-Tocopherol & $0.50 \pm 0.10^{\mathrm{b}}$ & $5.20 \pm 0.01^{\mathrm{a}}$ & nd \\
\hline Total tocopherols ( $\mu \mathrm{g} / \mathrm{g} \mathrm{dw})$ & $13.10 \pm 1.08^{\mathrm{b}}$ & $8.60 \pm 0.10^{c}$ & $60.57 \pm 3.23^{\mathrm{a}}$ \\
\hline Fructose & $83.23 \pm 7.71^{\mathrm{a}}$ & $18.30 \pm 1.27^{\mathrm{b}}$ & $7.35 \pm 1.06^{\mathrm{c}}$ \\
\hline Glucose & $26.70 \pm 1.13^{\mathrm{b}}$ & $15.65 \pm 2.62^{\mathrm{c}}$ & $29.75 \pm 0.92^{\mathrm{a}}$ \\
\hline Sucrose & $23.75 \pm 1.34^{\mathrm{b}}$ & nd & $41.45 \pm 0.21^{\mathrm{a}}$ \\
\hline Total sugars (mg/g dw) & $133.70 \pm 7.50^{\mathrm{a}}$ & $33.95 \pm 3.89^{c}$ & $78.55 \pm 2.19^{\mathrm{b}}$ \\
\hline Oxalic acid & $1.39 \pm 0.02^{\mathrm{b}}$ & $10.64 \pm 0.04^{\mathrm{a}}$ & $1.22 \pm 0.15^{\mathrm{b}}$ \\
\hline Malic acid & $3.23 \pm 0.90^{\mathrm{b}}$ & $12.33 \pm 0.55^{\mathrm{a}}$ & $2.23 \pm 0.10^{\mathrm{b}}$ \\
\hline Ascorbic acid & nd & nd & $0.24 \pm 0.01$ \\
\hline Shikimic acid & $0.71 \pm 0.01$ & nd & nd \\
\hline Citric acid & $5.99 \pm 0.35^{\mathrm{a}}$ & $2.40 \pm 0.01^{\mathrm{b}}$ & nd \\
\hline Succinic acid & nd & nd & $10.29 \pm 0.34$ \\
\hline Fumaric acid & nd & $0.28 \pm 0.01^{\mathrm{b}}$ & $0.49 \pm 0.01^{\mathrm{a}}$ \\
\hline Total organic acids (mg/g dw) & $11.32 \pm 1.26^{\mathrm{c}}$ & $25.65 \pm 0.51^{\mathrm{a}}$ & $13.98 \pm 0.47^{\mathrm{b}}$ \\
\hline
\end{tabular}

nd: not detected; dw: dry weight. In each row, different letters mean significant differences $(P<0.05)$.

As far as we know this is the first report on tocopherols composition of C. citratus and G. globosa; otherwise, the values obtained for $P$. tridentatum were similar to the ones described by the authors for a wild traditionally shade-dried sample $(8.8 \mu \mathrm{g} / \mathrm{g} \mathrm{dw})[8]$. Furthermore, tocopherols have also been reported in other species of the Fabaceae family, such as Cicer arietinum, Lathyrus sativus [18], Cytisus multiflorus, Cytisus scoparius, and Cytisus striatus [8]; and the amounts found ranged between 6.3 and $23.1 \mathrm{mg} / 100 \mathrm{~g}$ of $\mathrm{dw}$, which is in the range of the sample studied herein, detecting all the isoforms. All isoforms of tocopherols have also been reported in Poaceae and Amaranthaceae families [19], but the quantities cannot be compared due to the units in which they are expressed.

Regarding free sugars, $P$. tridentatum showed the highest levels of fructose and total sugars; nevertheless, the values obtained were much higher than the concentrations found in a wild sample previously studied $(0.3$ and $49.6 \mathrm{~g} / 100 \mathrm{~g} \mathrm{dw}$ for fructose and total sugars, resp.) [8]. This could be due to different growth conditions of the plants (e.g., variability of weather and soil characteristics are major factors affecting plant development) and to different drying processes applied, which influence moisture content and plant material quality. Pinela et al. [8] simulated consumers' traditional conditions of use (shade-drying, plant material being stored in a dark, dry place and at room temperature for 30 days); dried plant material used for analysis in this study was processed in five days under the best conditions of shade, daily temperature, and relative humidity as well as airflow rate. Furthermore, the presence of sugars has also been reported in the Poaceae family, namely, sucrose, glucose, fructose, trehalose, and raffinose, but the amounts obtained cannot be compared to the ones studied herein [20]. Some species belonging to the Fabaceae family (mentioned above) $[8,18]$ have also shown the presence of sugars, mainly fructose, glucose, sucrose, and trehalose, although some species revealed the presence of other sugars. The amounts found ranged between 2.56 and $18.67 \mathrm{~g} / 100 \mathrm{~g}$ of dw; these results are much lower than the one present in this study.

It should be highlighted that fructose can display antioxidant properties due to its reducing capacity. Furthermore, sugars are one of the molecules present in plant infusions that contribute to their energetic value [21]. C. citratus gave the highest levels of glucose and sucrose (Table 1 and Figure 1(b)). No reports were found considering sugars composition in the mentioned species or in G. globosa.

Concerning organic acids, G. globosa was the sample with the highest concentration of these compounds, mainly malic and oxalic acids (Table 1 and Figure 1(c)). Citric and succinic acids were found in higher levels in P. tridentatum and C. citratus, respectively. The latter also presented ascorbic acid, a powerful antioxidant phytochemical $[22,23]$. Besides their important role in the human metabolism, organic acids have other applications; for example, citric acid is a crystal thickener in bones, succinic acid is known to help in diabetes treatment, and malic acid is reported to have a bactericidal effect [24].

Among the three analyzed species, only $P$. tridentatum was previously studied regarding organic acids composition [15]; despite the fact that similar total amount was found $(8.1 \mathrm{mg} / \mathrm{g} \mathrm{dw})$, the profile then described was slightly different, reporting also the presence of quinic, succinic, and fumaric acids. As mentioned before, differences may be caused by distinct ecological conditions for plant development (plant material provenance is quite different) and also by different characteristics of the plant material used for analysis, as a consequence of the drying processes applied to each material. A five-day controlled in-storage process may produce a better quality plant material, in terms of color (visually confirmed), texture, and moisture content, 


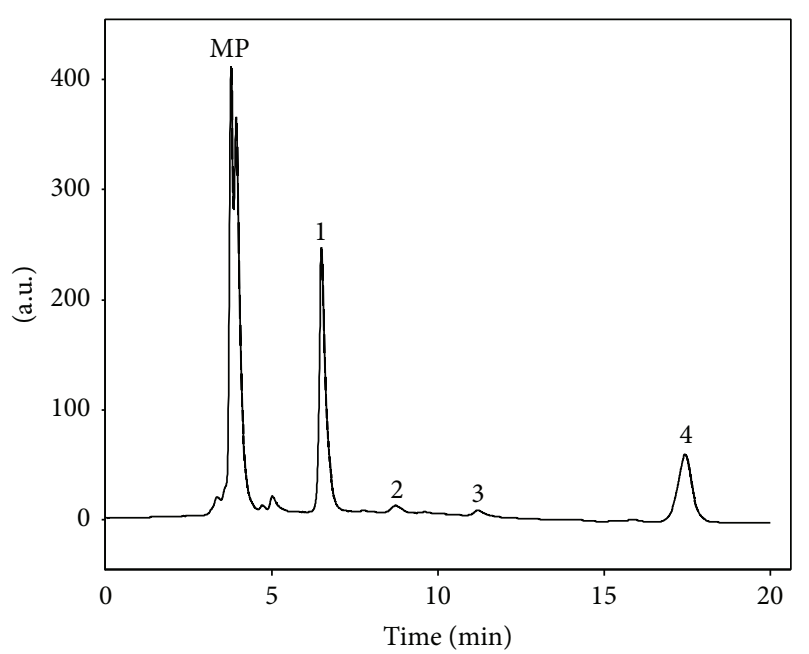

(a)

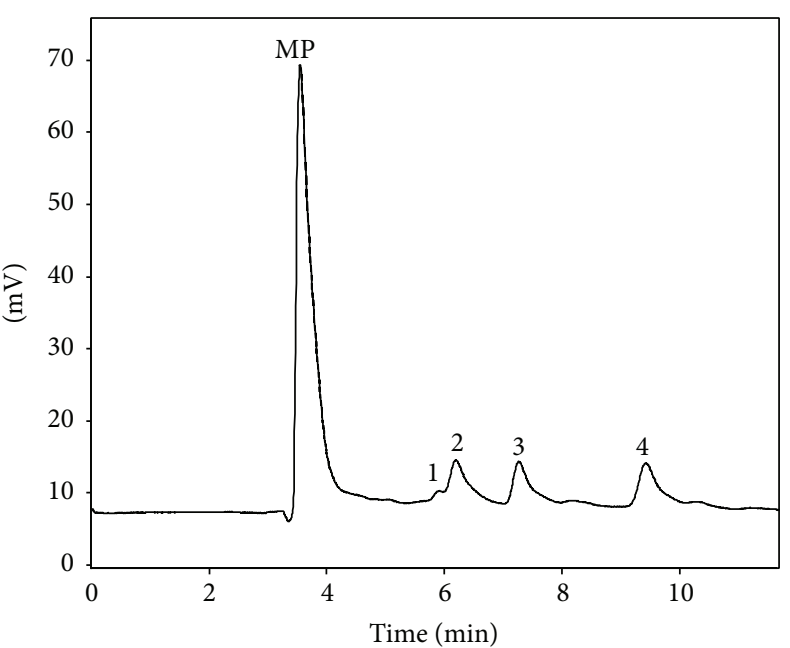

(b)

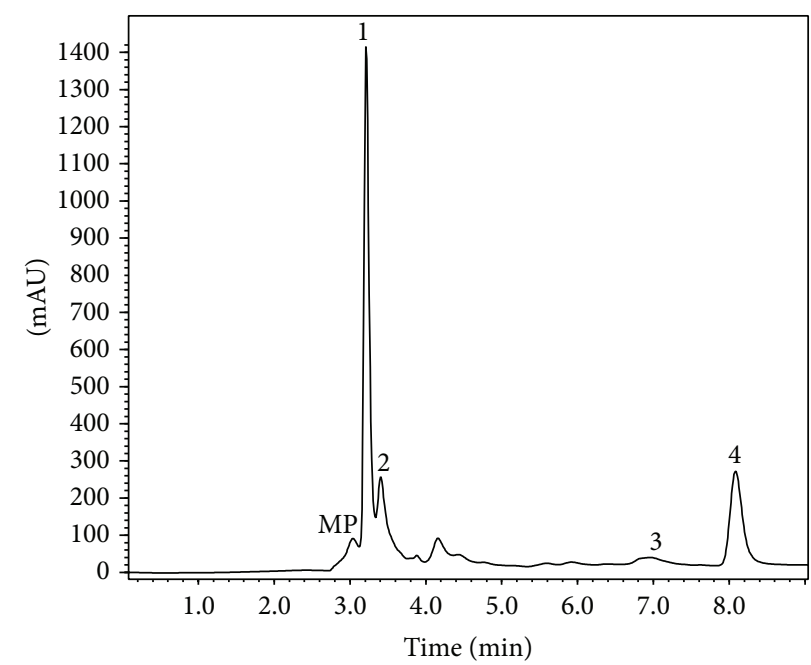

(c)

FIGURE 1: Chromatographic profile of (a) tocopherols in Gomphrena globosa obtained using HPLC-FD: 1: $\alpha$-tocopherol, 2: BHT, 3: $\gamma$ tocopherol, and 4: tocol (IS); (b) sugars in Cymbopogon citratus obtained using HPLC-RI: 1: fructose, 2: glucose, 3: sucrose, and 4: melezitose (IS); (c) organic acids in Gomphrena globosa obtained using UFLC-PDA: 1: oxalic acid, 2: malic acid, 3: citric acid, and 4: fumaric acid. MP: mobile phase.

than the traditional shade-drying techniques. All the organic acids, with the exception of quinic acid, have been previously reported in some species (mentioned above) belonging to the Fabaceae family $[8,18]$, although the quantities present have a large variation depending on the species.

\section{Conclusion}

Overall, C. citratus possessed the highest content of $\alpha$ - and total tocopherols, glucose, sucrose, succinic, and ascorbic acids. Pterospartum tridentatum presented the highest fructose and total sugars content. Otherwise, G. globosa showed the highest organic acids concentration, due to the highest content of oxalic and malic acids. This study is of great importance because it fills an existing void in relation to chemical characterization of these plants, more precisely its composition in sugars, organic acids, and tocopherols, that can be present in the consumed forms (mostly infusions).

\section{Conflict of Interests}

The authors declare that they have no conflict of interests.

\section{Acknowledgments}

The authors aregrateful to Foundation for Science and Technology (FCT, Portugal) for financial support to the research center CIMO (strategic project PEst-OE/AGR/UI0690/2011) and Lillian Barros researcher contract under "Programa Compromisso com Ciência, 2008." 


\section{References}

[1] M. H. Novais, I. Santos, S. Mendes, and C. Pinto-Gomes, "Studies on pharmaceutical ethnobotany in Arrabida Natural Park (Portugal)," Journal of Ethnopharmacology, vol. 93, no. 2-3, pp. 183-195, 2004.

[2] J. M. Neves, C. Matos, C. Moutinho, G. Queiroz, and L. R. Gomes, "Ethnopharmacological notes about ancient uses of medicinal plants in Trás-os-Montes (northern of Portugal)," Journal of Ethnopharmacology, vol. 124, no. 2, pp. 270-283, 2009.

[3] L. R. Silva, P. Valentão, J. Faria et al., "Phytochemical investigations and biological potential screening with cellular and non-cellular models of globe amaranth (Gomphrena globosa L.) inflorescences," Food Chemistry, vol. 135, no. 2, pp. 756-763, 2012.

[4] A. M. Rahman and M. I. A. Gulshana, "Taxonomy and medicinal uses on amaranthaceae family of Rajshahi, Bangladesh," Applied Ecology and Environmental Sciences, vol. 2, no. 2, pp. 54-59, 2014.

[5] R. R. B. Negrelle and E. C. Gomes, "Cymbopogon citratus (DC.) Stapf: chemical composition and biological activities," Revista Brasileira de Plantas Medicinais, vol. 9, no. 1, pp. 80-92, 2007.

[6] V. Francisco, G. Costa, A. Figueirinha et al., "Anti-inflammatory activity of Cymbopogon citratus leaves infusion via proteasome and nuclear factor- $\kappa \mathrm{B}$ pathway inhibition: contribution of chlorogenic acid," Journal of Ethnopharmacology, vol. 148, no. 1, pp. 126-134, 2013.

[7] V. Francisco, A. Figueirinha, B. M. Neves et al., "Cymbopogon citratus as source of new and safe anti-inflammatory drugs: bio-guided assay using lipopolysaccharide-stimulated macrophages," Journal of Ethnopharmacology, vol. 133, no. 2, pp. 818-827, 2011.

[8] J. Pinela, L. Barros, A. M. Carvalho, and I. C. F. R. Ferreira, "Influence of the drying method in the antioxidant potential and chemical composition of four shrubby flowering plants from the tribe Genisteae (Fabaceae)," Food and Chemical Toxicology, vol. 49, no. 11, pp. 2983-2989, 2011.

[9] C. L. Roriz, L. Barros, A. M. Carvalho, C. Santos-Buelga, and I. C. F. R. Ferreira, "Pterospartum tridentatum, Gomphrena globosa and Cymbopogon citratus: a phytochemical study focused on antioxidant compounds," Food Research International, vol. 62, pp. 684-693, 2014.

[10] E. Hernandez-Marin and A. Martínez, "Carbohydrates and their free radical scavenging capability: a theoretical study," The Journal of Physical Chemistry B, vol. 116, no. 32, pp. 9668-9675, 2012.

[11] J. Lopez-Bucio, M. F. Nieto-Jacobo, V. Ramírez-Rodríguez, and L. Herrera-Estrella, "Organic acid metabolism in plants: From adaptive physiology to transgenic varieties for cultivation in extreme soils," Plant Science, vol. 160, no. 1, pp. 1-13, 2000.

[12] Q. Jiang, "Natural forms of vitamin E: metabolism, antioxidant, and anti-inflammatory activities and their role in disease prevention and therapy," Free Radical Biology and Medicine, vol. 72, pp. 76-90, 2014.

[13] M. I. Dias, L. Barros, M. J. Sousa, and I. C. F. R. Ferreira, "Comparative study of lipophilic and hydrophilic antioxidants from in vivo and in vitro grown Coriandrum sativum," Plant Foods for Human Nutrition, vol. 66, no. 2, pp. 181-186, 2011.

[14] J. C. M. Barreira, J. A. Pereira, M. B. P. P. Oliveira, and I. C. F. R. Ferreira, "Sugars profiles of different chestnut (Castanea sativa Mill.) and almond (Prunus dulcis) cultivars by HPLC-RI," Plant Foods for Human Nutrition, vol. 65, no. 1, pp. 38-43, 2010.
[15] C. Pereira, L. Barros, A. M. Carvalho, and I. C. F. R. Ferreira, "Use of UFLC-PDA for the analysis of organic acids in thirty five species of food and medicinal plants," Food Analytical Methods, vol. 6, no. 5, pp. 1337-1344, 2013.

[16] O. Ouchikh, T. Chahed, R. Ksouri et al., "The effects of extraction method on the measured tocopherol level and antioxidant activity of L. nobilis vegetative organs," Journal of Food Composition and Analysis, vol. 24, no. 1, pp. 103-110, 2011.

[17] Y. Yang and D. J. McClements, "Encapsulation of vitamin E in edible emulsions fabricated using a natural surfactant," Food Hydrocolloids, vol. 30, no. 2, pp. 712-720, 2013.

[18] A. Sarmento, L. Barros, Â. Fernandes, A. M. Carvalho, and I. C. Ferreira, "Valorization of traditional foods: nutritional and bioactive properties of Cicer arietinum L. and Lathyrus sativus L. pulses," Journal of the Science of Food and Agriculture, 2014.

[19] G. Horvath, L. Wessjohann, J. Bigirimana et al., "Differential distribution of tocopherols and tocotrienols in photosynthetic and non-photosynthetic tissues," Phytochemistry, vol. 67, no. 12, pp. 1185-1195, 2006.

[20] H. R. Ghasempour, D. F. Gaff, R. P. W. Williams, and R. D. Gianello, "Contents of sugars in leaves of drying desiccation tolerant flowering plants, particularly grasses," Plant Growth Regulation, vol. 24, no. 3, pp. 185-191, 1998.

[21] D. Komes, A. Belščak-Cvitanović, I. Ljubičić et al., "Formulating blackberry leaf mixtures for preparation of infusions with plant derived sources of sweeteners," Food Chemistry, vol. 151, pp. 385-393, 2014.

[22] I. C. F. R. Ferreira, L. Barros, and R. Abreu, "Antioxidants in wild mushrooms," Current Medicinal Chemistry, vol. 16, no. 12, pp. 1543-1560, 2009.

[23] B. Halliwell, "Free radicals and antioxidants: updating a personal view," Nutrition Reviews, vol. 70, no. 5, pp. 257-265, 2012.

[24] M. Carocho, L. Barros, A. L. Antonio et al., "Analysis of organic acids in electron beam irradiated chestnuts (Castanea sativa Mill.): effects of radiation dose and storage time," Food and Chemical Toxicology, vol. 55, pp. 348-352, 2013. 

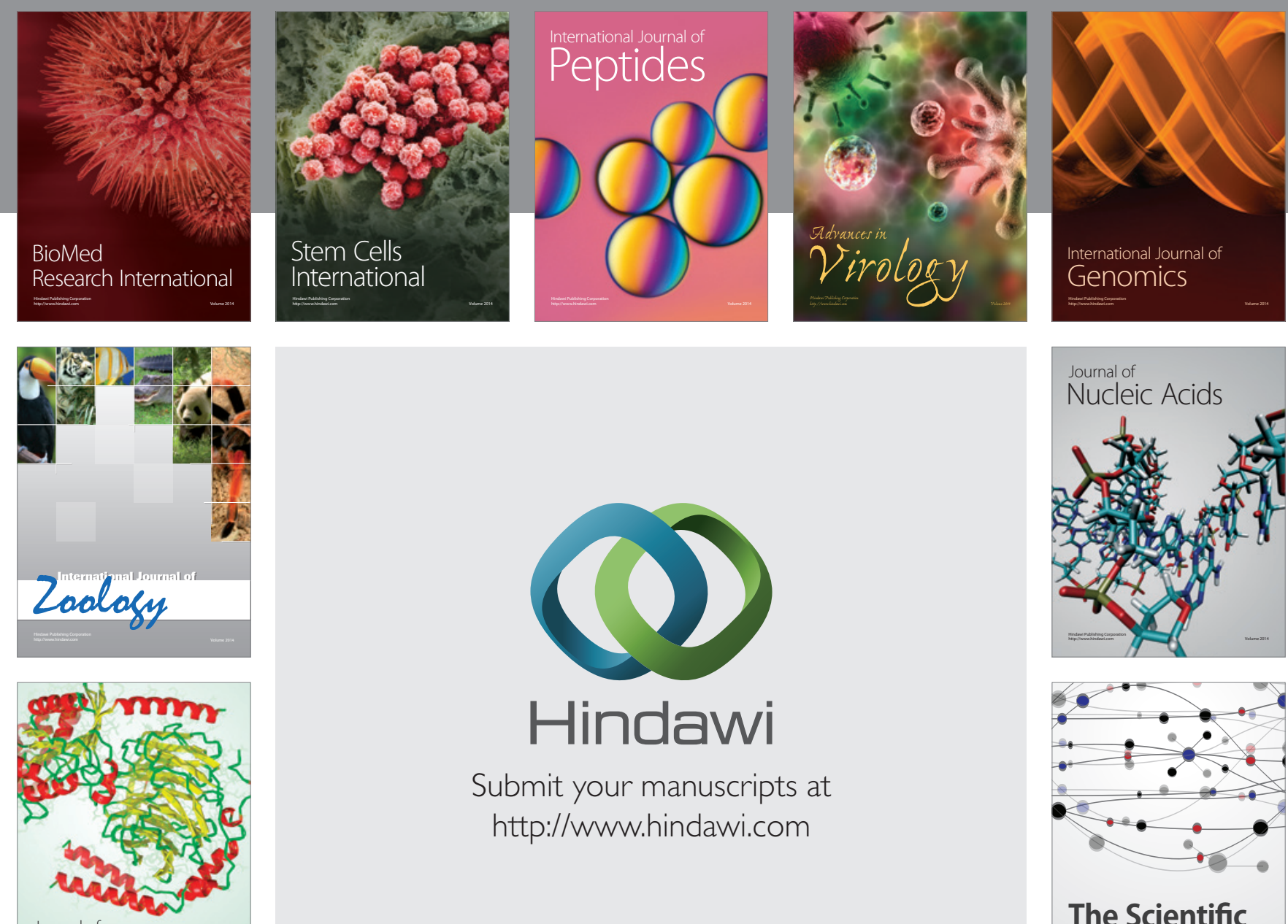

Submit your manuscripts at

http://www.hindawi.com

Journal of
Signal Transduction
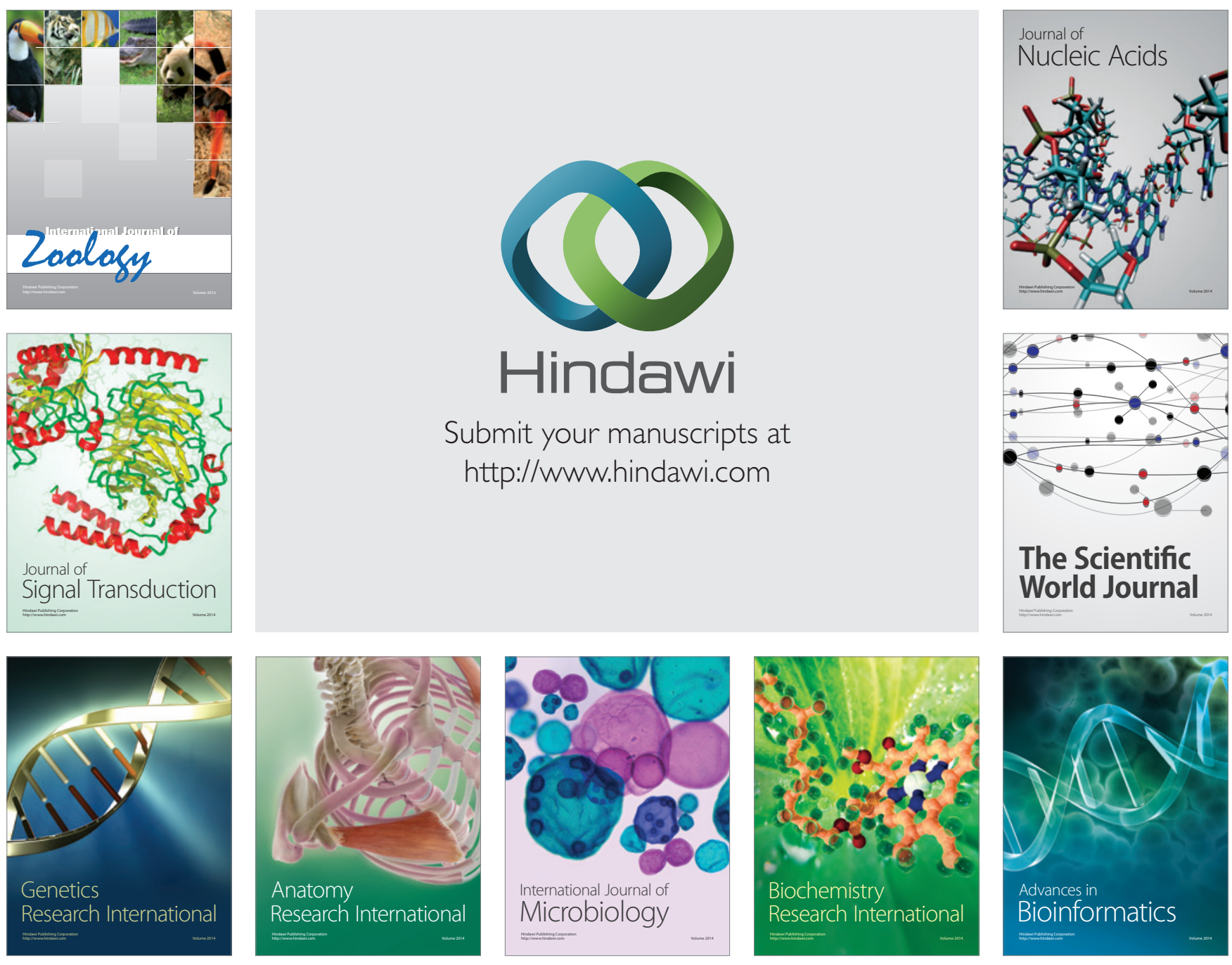

The Scientific World Journal
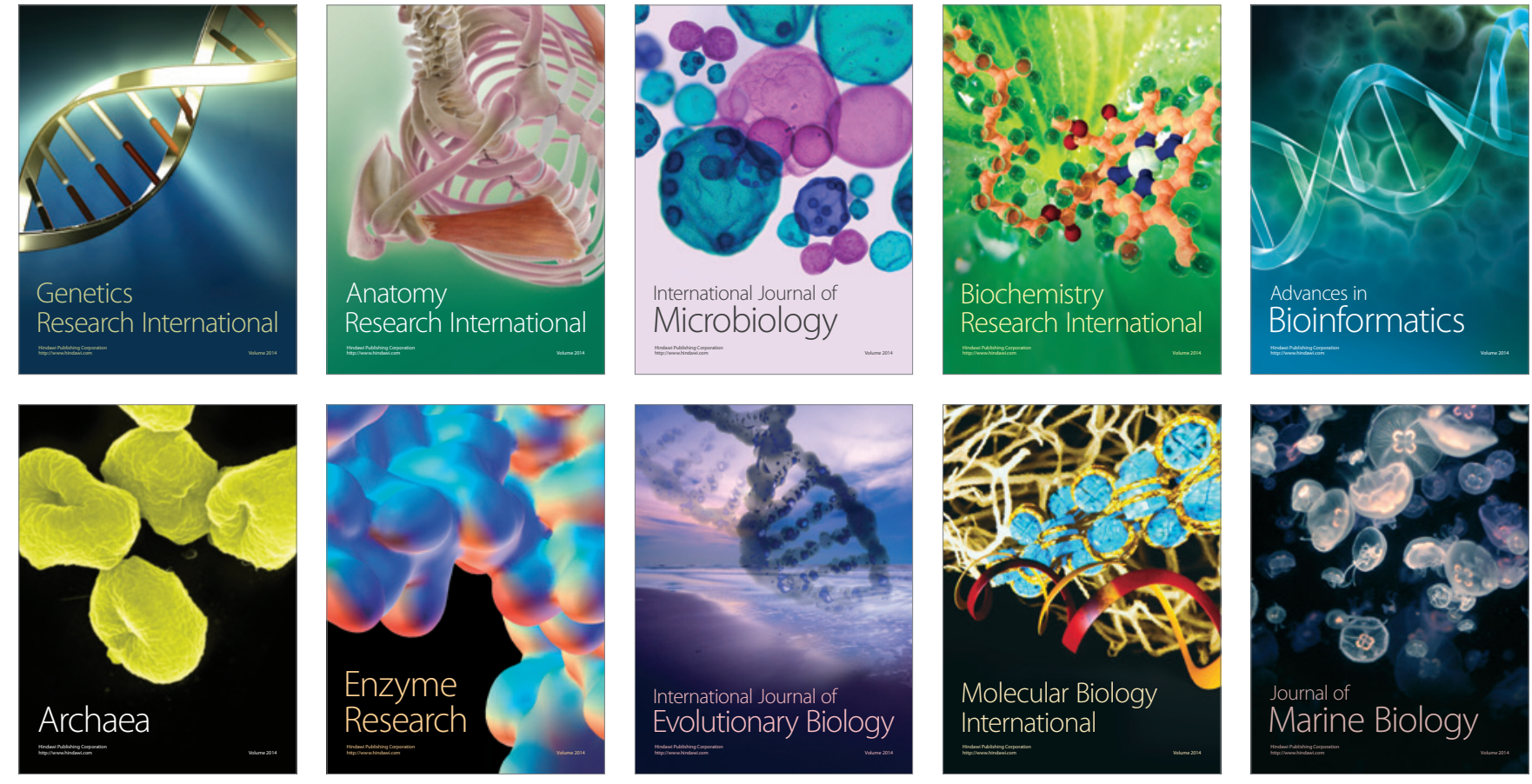